\title{
Effects of Coiling Temperature on the Microstructures, Mechanical Properties and Textures of 08Al Deep Drawing Steel Sheet
}

\author{
Feng Shi ${ }^{1}$, Bao-Cai $\mathrm{Wu}^{2}$, Da-Peng $\mathrm{Yin}^{3}$, Yang $\mathrm{Qi}^{1}$, Xiao-Wu $\mathrm{Li}^{1, *}$ and Chun-Ming $\mathrm{Liu}^{3, *}$ \\ ${ }^{1}$ Institute of Materials Physics and Chemistry, Northeastern University, Shenyang 110819, China \\ ${ }^{2}$ Alar 359 Iron and Steel Co. Ltd., Alar 843300, China \\ ${ }^{3}$ College of Materials and Metallurgy, Northeastern University, Shenyang 110819, China
}

\begin{abstract}
Effects of the coiling temperature on the microstructures and mechanical properties of 08Al hot-rolled steel sheet were investigated. Meanwhile, cold rolling and annealing experimental verifications were performed in the laboratory. The results show that when coiling is carried out at $592^{\circ} \mathrm{C}$, the hot-rolled steel sheet exhibits good comprehensive mechanical properties. After cold rolling and annealing treatments, the experimental steel sheet also shows the optimal deep-drawability. The volume fraction of $\{111\}\langle U V W\rangle$ texture component is the highest and the values of $\{111\}\langle U V W\rangle /\{001\}\langle 110\rangle$ and $\{111\}\langle U V W\rangle /\{001\}\langle 100\rangle$ are both the largest. However, the strip-like or massive cementites appear in the steel sheet as the coiling temperature is higher than $620^{\circ} \mathrm{C}$, which is harmful to the deep-drawability of the experimental steel. Therefore, the coiling temperature should be controlled to be lower than $620^{\circ} \mathrm{C}$ in the $08 \mathrm{Al}$ deep drawing steel sheet. [doi:10.2320/matertrans.M2015150]
\end{abstract}

(Received April 16, 2015; Accepted July 23, 2015; Published September 4, 2015)

Keywords: $08 \mathrm{Al}$ deep drawing steel sheet, coiling temperature, microstructure, mechanical property, texture

\section{Introduction}

The production of the 08Al cold-rolled deep drawing steel needs generally go through a complex process, involving smelting, hot rolling, pickling, cold rolling, annealing and smooth. The rigorous control of each working procedure affects the final quality of products. High plastic strain ratio, large work hardening exponent, low yield strength, low yield ratio and strong $\{111\}\langle U V W\rangle$ texture are all the important specifications of the cold-rolled deep drawing steel, while strong $\{111\}\langle U V W\rangle$ texture is the most critical factor for obtaining an excellent deep drawing property in the $08 \mathrm{Al}$ cold-rolled deep drawing steel. ${ }^{1)}$ This kind of favorable texture is controlled by the AIN precipitation, which is dependent upon the coiling temperature during hot rolling. The numerous research and production practice have demonstrated that the heating-up temperature, beginning temperature, finishing temperature and coiling temperature are all the parameters necessary to be controlled in $08 \mathrm{Al}$ coldrolled deep drawing steel. ${ }^{2-7)}$ However, the choice of coiling temperature is crucial for the deep-drawability of cold-rolled productions. The main purpose of controlling coiling temperature is to prevent AIN precipitation during coiling but to make AlN precipitate during annealing, and thus to control the orientation of the recrystallized grains to form the strong $\{111\}\langle U V W\rangle$ texture. $^{8-13)}$ In this work, the effects of the coiling temperature on the microstructure, mechanical property and texture of 08Al cold-rolled deep drawing steel are investigated. The research findings will provide some theoretical basis for the hot working technology of the experimental steel.

\section{Experimental Procedures}

The experimental steels used in the present study are the

*Corresponding author, E-mail: xwli@mail.neu.edu.cn, cmliu@mail.neu. edu.cn
Table 1 Chemical composition of experimental steel (mass\%).

\begin{tabular}{ccccccc}
\hline $\mathrm{C}$ & $\mathrm{Si}$ & $\mathrm{Mn}$ & $\mathrm{P}$ & $\mathrm{S}$ & $\mathrm{Al}_{\mathrm{s}}$ & $\mathrm{Fe}$ \\
\hline$\leq 0.08$ & $\leq 0.03$ & $\leq 0.40$ & $\leq 0.02$ & $\leq 0.03$ & $0.015-0.08$ & Balanced \\
\hline
\end{tabular}

hot-rolled sheets with $3 \mathrm{~mm}$ in thickness and $720 \mathrm{~mm}$ in width. The coiling temperatures are 531, 563, 592, 620, 643 and $709^{\circ} \mathrm{C}$, respectively. The chemical composition of the experimental steel is shown in Table 1.

The hot-rolled sheets with different coiling temperatures were cut along the rolling direction, the transverse direction and the direction making an angle of $45^{\circ}$ to the rolling direction, respectively. Then the standard tensile specimens with the size of $140 \mathrm{~mm} \times 20 \mathrm{~mm} \times 3 \mathrm{~mm}$ (gage area size $50 \mathrm{~mm} \times 12.5 \mathrm{~mm} \times 3 \mathrm{~mm}$ ) were prepared for uniaxial tensile testing at room temperature with a stain rate of $10^{-3} \mathrm{~s}^{-1}$. Nine specimens (three specimens in each direction) were used for each condition and the average value of the measured data was calculated as the final value. The clamping part of the tensioned specimens was cut into small samples with the dimension of $10 \mathrm{~mm} \times 10 \mathrm{~mm} \times 3 \mathrm{~mm}$. After etching the samples using the solution of $\mathrm{HNO}_{3}$ and alcohol, microstructures were observed by Olympus GX 71 optical microscopy (OM). Then the cold-rolling and simulated batch annealing experiments were proceeded in the laboratory simulating large-scale production. Specifically, the hot-rolled sheets were pickled and cold rolled from $3 \mathrm{~mm}$ to $0.8 \mathrm{~mm}$ in thickness on a 4-high-rolling mill in the laboratory, and then box annealed. The specimens were heated from room temperature to $510^{\circ} \mathrm{C}$ by $5 \mathrm{~h}$, and then heated from $510^{\circ} \mathrm{C}$ to $690^{\circ} \mathrm{C}$ with a heating rate of $30^{\circ} \mathrm{C} / \mathrm{h}$, keeping for $1 \mathrm{~h}$, followed by the furnace cooling to $70^{\circ} \mathrm{C}$ and then air cooling. The same microstructure observation and mechanical test were carried out on the annealed specimens as the case of the hot-rolled specimens. Textures were measured on a X'Pert MRD X-ray diffractometer (XRD). 

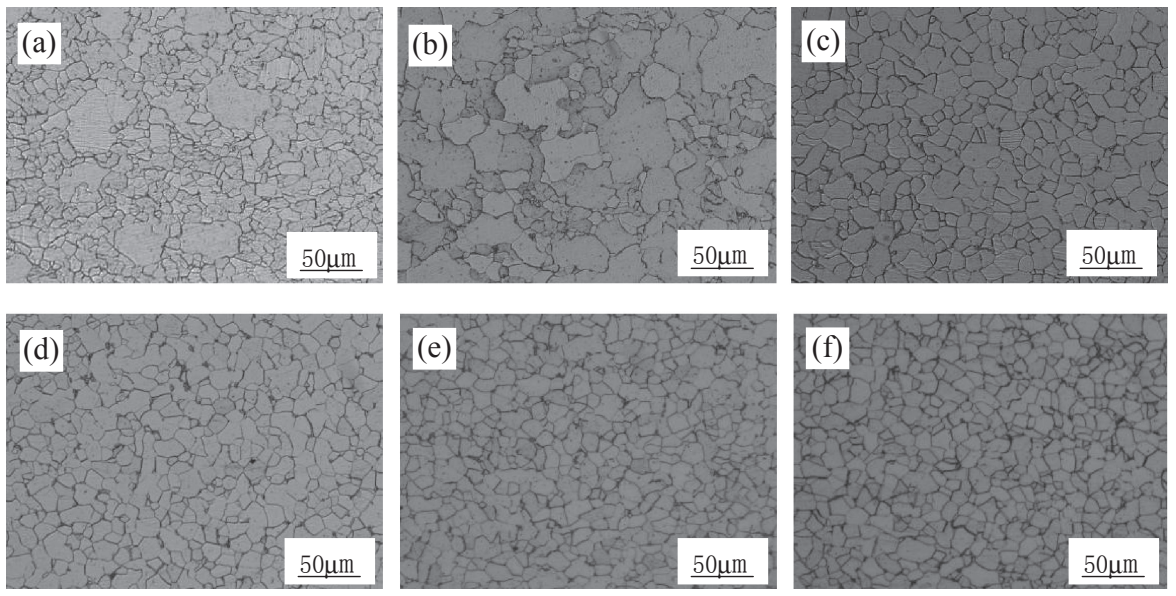

Fig. 1 Low-magnification optical microstructures for the $08 \mathrm{Al}$ hot-rolled sheets coiled at different temperatures. (a) $5311^{\circ} \mathrm{C}$; (b) $563^{\circ} \mathrm{C}$; (c) $592^{\circ} \mathrm{C}$; (d) $620^{\circ} \mathrm{C}$; (e) $643^{\circ} \mathrm{C}$; (f) $709^{\circ} \mathrm{C}$.
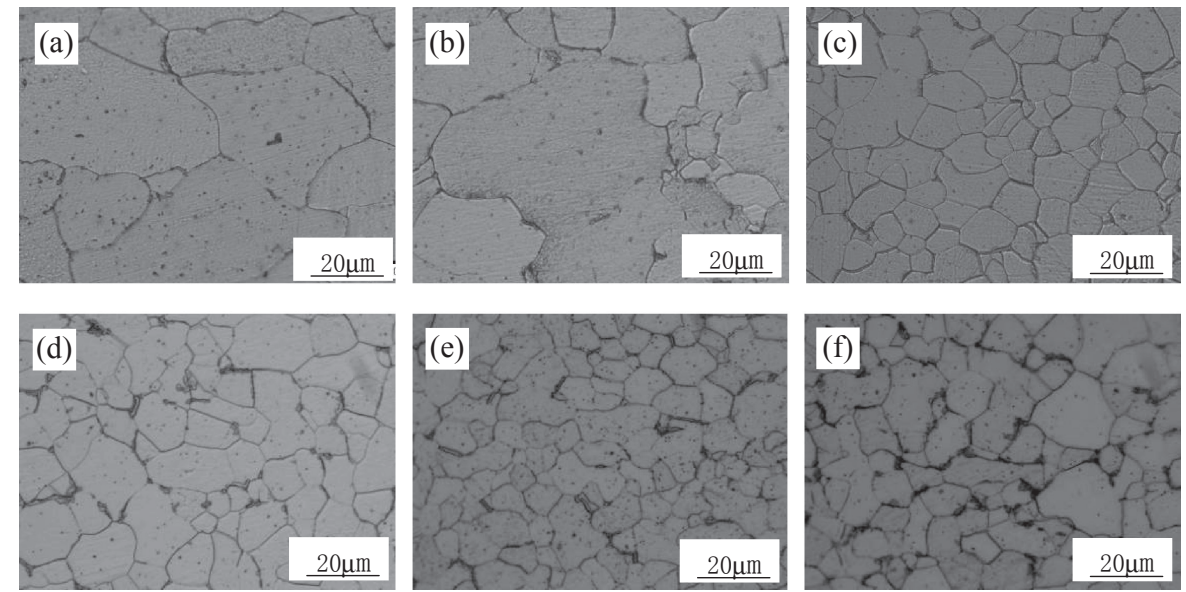

Fig. 2 High-magnification optical microstructures for the $08 \mathrm{Al}$ hot-rolled sheets coiled at different temperatures. (a) $531{ }^{\circ} \mathrm{C}$; (b) $563^{\circ} \mathrm{C}$; (c) $592^{\circ} \mathrm{C}$; (d) $620^{\circ} \mathrm{C}$; (e) $643^{\circ} \mathrm{C}$; (f) $709^{\circ} \mathrm{C}$.

\section{Results and Discussion}

\subsection{The effects of coiling temperature on the micro- structures and mechanical properties in 08Al hot- rolled sheet}

Figure 1 shows the low-magnification optical microstructures of $08 \mathrm{Al}$ hot-rolled steel sheets with different coiling temperatures. When coiled at $531^{\circ} \mathrm{C}$ and $563^{\circ} \mathrm{C}$, the grains with an inhomogeneous size distribution form in the microstructures (Fig. 1(a) and (b)). When the coiling temperature is in the range of $592-709^{\circ} \mathrm{C}$, distortion degree of the grains reduces, the proportion of the equiaxed grains increases and the grains become finer (Fig. 1(c)-(f)).

Figure 2 shows the high-magnification optical microstructures of the $08 \mathrm{Al}$ hot-rolled steel sheets with different coiling temperatures. From Fig. 2 it can be seen that the morphology, distribution and number of cementites are dependent upon the coiling temperatures. When coiled at $531^{\circ} \mathrm{C}$ and $563^{\circ} \mathrm{C}$, the cementites precipitated at grain boundaries (GBs) are smaller and granular cementite precipitates also occur inside grains (Fig. 2(a) and (b)). When coiled at $592^{\circ} \mathrm{C}$, the cementites precipitate both in the interior of grains and at GBs (Fig. 2(c)). When coiled at the temperatures ranging from $620^{\circ} \mathrm{C}$ to $709^{\circ} \mathrm{C}$, the strip-like or massive cementites were obviously found along GBs (Fig. 2(d)-(f)). Accordingly, it can be inferred that the cementites are easy to precipitate at GBs and much coarser at the higher coiling temperatures.

The requirement of cold-rolled drawing steel sheet for the hot-rolling microstructure is that grains are homogeneous and fine, and meanwhile the cementites at GBs should not be coarse. The variation in coiling temperature induces the change of the hot-rolling microstructure and directly affects the grain size and the precipitation of cementites in the experimental steel. For the precipitation of cementites in the hot-rolling microstructure, the lower coiling temperature leads to the smaller action capability of atom and the slower precipitation process, and the precipitated cementites are thus thinner. When the coiling temperature is elevated, the precipitation of cementites becomes easier. From Fig. 2 it can be obviously seen that the precipitation amount of cementites in the specimen under the higher coiling temperature is much greater than that under the lower coiling temperature. The precipitation of the cementite hinders the growth of ferrite grains, so that the grains of the experimental steel coiled at the temperature between $592^{\circ} \mathrm{C}$ and $709^{\circ} \mathrm{C}$ become much more homogeneous and finer (Fig. 1(c)-(f)). However, the cementites at GBs are gradually coarsened and accumulated 


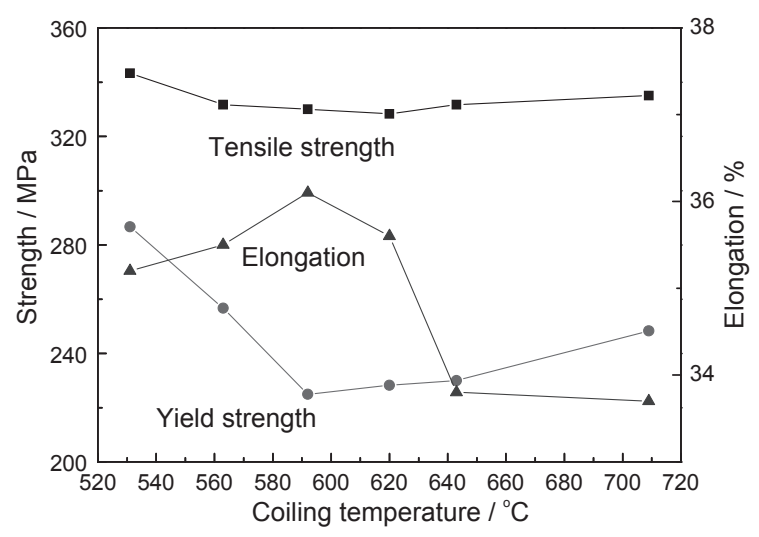

Fig. 3 The change in mechanical properties of the 08Al hot-rolled sheet with the coiling temperature.

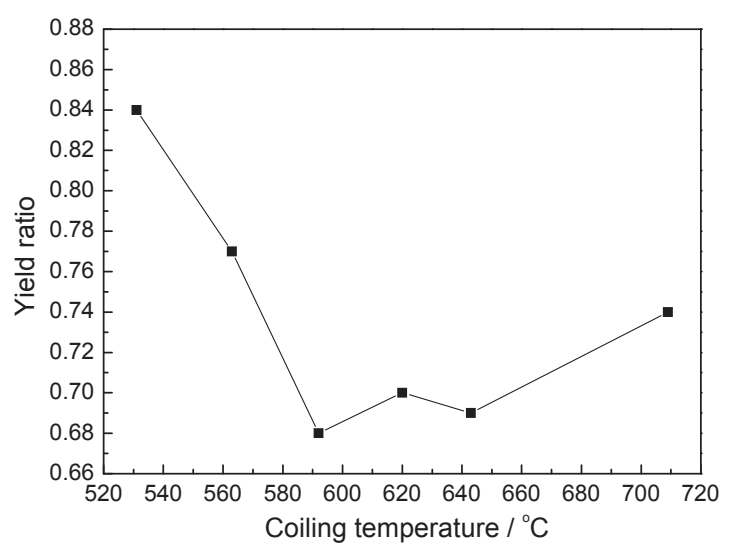

Fig. 4 The change in yield ratio of the $08 \mathrm{Al}$ hot-rolled sheet with the coiling temperature.
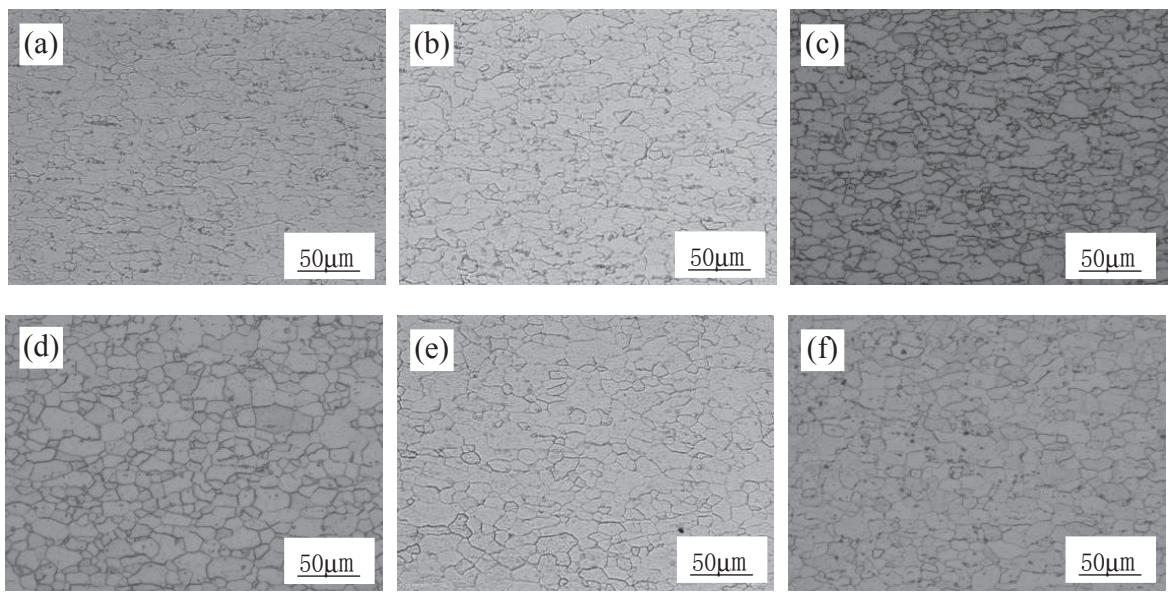

Fig. 5 Low-magnification metallographs of the 08Al hot-rolled sheets coiled at different temperatures subjected to cold rolling and annealing. (a) $531^{\circ} \mathrm{C}$; (b) $563^{\circ} \mathrm{C}$; (c) $592^{\circ} \mathrm{C}$; (d) $620^{\circ} \mathrm{C}$; (e) $643^{\circ} \mathrm{C}$; (f) $709^{\circ} \mathrm{C}$.

as the coiling temperature increases, and the strip-like or massive cementites are then formed as the coiling temperature is higher than $620^{\circ} \mathrm{C}$ (Fig. 2(d)-(f)). Based on the above experimental results it can be determined that the microstructure coiled at $592^{\circ} \mathrm{C}$ is ideal for the hot-rolling process.

Figure 3 shows the variation in the mechanical properties (yield strength $\left(\sigma_{\mathrm{YS}}\right)$, tensile strength $\left(\sigma_{\mathrm{UTS}}\right)$ and elongation $(\delta))$ with the coiling temperature in the $08 \mathrm{Al}$ hot-rolled sheet. It can be found that both the yield strength and tensile strength firstly decrease and then increase with increasing coiling temperature, and the yield strength is the lowest at $592^{\circ} \mathrm{C}$. The elongation firstly increases and then decreases as the coiling temperature increases, and reaches the highest value at $592^{\circ} \mathrm{C}$.

Figure 4 shows the variation curve of yield ratio vs. coiling temperature in the $08 \mathrm{Al}$ hot-rolled sheet. It can be seen that the yield ratio firstly decreases and then increases with increasing coiling temperature and reaches the lowest value at $592^{\circ} \mathrm{C}$. That's to say, the $08 \mathrm{Al}$ hot-rolled steel sheet exhibits a synergy of strength and ductility at a coiling temperature of $592^{\circ} \mathrm{C}$.

The cold rolling and the simulated batch annealing experiment were carried on in order to verify the possibility for obtaining an optimal deep-drawability in the experimental steel coiled at $592^{\circ} \mathrm{C}$.
3.2 The effects of coiling temperature on the microstructures, mechanical properties and textures in $08 \mathrm{Al}$ cold-rolled sheet

Figure 5 shows the low-magnification optical microstructures of the hot-rolled steel sheets coiled at different temperatures after cold-rolling and annealing treatments. Obviously, grains are fine but inhomogeneous when coiled at $531^{\circ} \mathrm{C}$ and $563^{\circ} \mathrm{C}$ (Fig. 5(a) and (b)), while grains become more homogeneous and pancake-shaped at $592^{\circ} \mathrm{C}$ (Fig. 5(c)). With further increasing coiling temperature, the shape of grains changes from pancake-like to equiaxed, and the proportion of equiaxed grains gradually increases (Fig. 5(d)(f)).

Figure 6 shows the high-magnification optical microstructures after cold-rolling and annealing of the hot-rolled sheets coiled at different temperatures. It can be observed that all microstructures consist of ferrites and cementites under different coiling temperatures. Thin chain cementites are dominant in the matrix in the samples coiled at $531^{\circ} \mathrm{C}$ and $563^{\circ} \mathrm{C}$ (Fig. 6(a) and (b)). The cementites are dispersively distributed in grains and at GBs in the sample coiled at $592^{\circ} \mathrm{C}$ (Fig. 6(c)). Some strip-like or massive cementites begin to appear at GBs as the coiling temperature rises (Fig. 6(d)-(f)).

For the sake of obtaining a good deep-drawability of coldrolled drawing steel sheet, the grain shape can be pancake- 

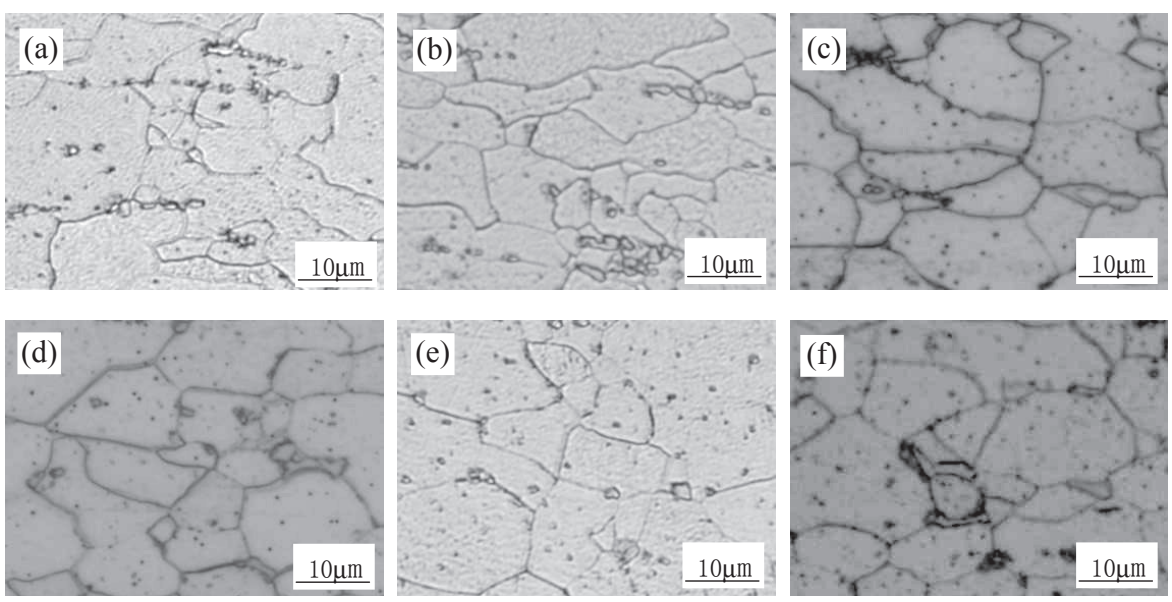

Fig. 6 High-magnification metallographs of the 08Al hot-rolled sheets coiled at different temperatures subjected to cold rolling and annealing. (a) $531^{\circ} \mathrm{C}$; (b) $563^{\circ} \mathrm{C}$; (c) $592^{\circ} \mathrm{C}$; (d) $620^{\circ} \mathrm{C}$; (e) $643^{\circ} \mathrm{C}$; (f) $709^{\circ} \mathrm{C}$.

like, and the grain size should be moderate and not too small. Moreover, the cementites at GBs should not be too coarse. Only in the case that the cementites are dispersively distributed in the ferrite matrix with a granular morphology, the stamping property of the steel will be better. The variation in coiling temperature induces the changes both in hot-rolling and cold-rolling microstructures, directly affecting the grain size, shape and the precipitation state of cementites in the cold-rolling microstructures. Under the higher coiling temperatures, AIN precipitates during coiling, and these fine AlN particles preferentially precipitated hinder the growth of grains and make the grains become equiaxed (Fig. 5(d)-(f)). The cementites at GBs will gradually become coarsened and accumulated, and strip-like or massive cementites will form eventually with increasing the coiling temperature to extremely high levels, e.g., above $620^{\circ} \mathrm{C}$ (Fig. 6(d)-(f)). Actually, these strip-like or massive cementites are induced by the heredity of hot-rolling microstructures (Fig. 2(d)-(f)), that's to say, the strip-like or massive cementites formed during hot rolling are crushed down during cold rolling to form many micro-voids around them. These micro-voids provide a large amount of spaces for the precipitation of cementites during annealing, compelling the coarse and massive cementites to distribute along GBs. These coarse cementites in the annealing microstructure would detrimentally affect the stamping performance of cold-rolled products.

Table 2 shows the mechanical properties of $08 \mathrm{Al}$ hotrolled sheets coiled at different temperatures after cold-rolling and annealing processes in three different directions (against the rolling direction at $0^{\circ}, 45^{\circ}$ and $90^{\circ}$ ). From Table 2 it can be seen that the difference in mechanical properties is large in three directions and the planar anisotropy is obvious, especially plastic strain ratio ( $r$ value). The $r$ value is the highest in the transverse direction (against the rolling direction at $90^{\circ}$ ) and the lowest in the direction making an angle of $45^{\circ}$ to the rolling direction. The $r$ value is an important index measuring deep drawing properties of steels, while the $r$ value of the deep drawing material is closely related to the nature of recrystallization textures. ${ }^{14)}$ The best orientation that provides good deep drawing properties is $\{111\}\langle U V W\rangle$ and the worst orientation is $\{001\}\langle U V W\rangle$. The
Table 2 Mechanical properties of the 08Al hot-rolled sheets in three different directions coiled at different temperatures subjected to cold rolling and annealing.

\begin{tabular}{ccccccc}
\hline $\begin{array}{c}\text { Coiling } \\
\text { temperature } \\
/{ }^{\circ} \mathrm{C}\end{array}$ & $\begin{array}{c}\text { Tensile } \\
\text { strength } \\
\text { /MPa }\end{array}$ & $\begin{array}{c}\text { Yield } \\
\text { strength } \\
/ \mathrm{MPa}\end{array}$ & $\begin{array}{c}\text { Yield } \\
\text { ratio }\end{array}$ & $\begin{array}{c}\text { Elongation } \\
/ \%\end{array}$ & $\begin{array}{c}n \\
\text { value }\end{array}$ & $\begin{array}{c}r \\
\text { value }\end{array}$ \\
\hline $531-0^{\circ}$ & 322 & 270 & 0.84 & 37.5 & 0.24 & 0.88 \\
$531-45^{\circ}$ & 330 & 280 & 0.85 & 34.8 & 0.24 & 0.86 \\
$531-90^{\circ}$ & 328 & 277 & 0.84 & 39.1 & 0.23 & 1.19 \\
531 -average & 327 & 276 & 0.84 & 37.1 & 0.24 & 0.95 \\
\hline $563-0^{\circ}$ & 323 & 272 & 0.84 & 40.5 & 0.24 & 0.9 \\
$563-45^{\circ}$ & 330 & 275 & 0.83 & 36.3 & 0.24 & 0.77 \\
$563-90^{\circ}$ & 325 & 265 & 0.82 & 39.3 & 0.25 & 1.82 \\
563 -average & 326 & 271 & 0.83 & 38.7 & 0.25 & 1.07 \\
\hline $592-0^{\circ}$ & 318 & 260 & 0.82 & 42.9 & 0.26 & 1.24 \\
$592-45^{\circ}$ & 320 & 263 & 0.82 & 39.4 & 0.25 & 1.25 \\
$592-90^{\circ}$ & 318 & 260 & 0.82 & 38.2 & 0.26 & 1.68 \\
592 -average & 319 & 261 & 0.82 & 40.2 & 0.26 & 1.36 \\
\hline $620-0^{\circ}$ & 320 & 266.7 & 0.83 & 42.8 & 0.26 & 0.93 \\
$620-45^{\circ}$ & 330 & 270 & 0.82 & 40.2 & 0.26 & 1.19 \\
$620-90^{\circ}$ & 320 & 256.7 & 0.80 & 39.5 & 0.27 & 1.82 \\
620 -average & 323.3 & 264.5 & 0.82 & 40.8 & 0.26 & 1.28 \\
\hline $643-0^{\circ}$ & 323.3 & 268.3 & 0.83 & 41.1 & 0.25 & 1.17 \\
$643-45^{\circ}$ & 325 & 266.7 & 0.82 & 38.9 & 0.25 & 1.06 \\
$643-90^{\circ}$ & 315 & 260 & 0.83 & 35.7 & 0.26 & 1.7 \\
709 -average & 319 & 256 & 0.80 & 38.0 & 0.25 & 1.27 \\
\hline $709-0^{\circ}$ & 318 & 255 & 0.80 & 38.1 & 0.25 & 1.09 \\
$709-45^{\circ}$ & 325 & 263 & 0.81 & 38.0 & 0.25 & 1 \\
$709-90^{\circ}$ & 315 & 250 & 0.79 & 37.9 & 0.25 & 1.97 \\
\hline & & & & & &
\end{tabular}

larger the fraction of $\{111\}$ texture and the smaller the fraction of $\{001\}$ texture, the higher $r$ value will be. ${ }^{8)}$

The corresponding variation curves of mechanical properties vs. coiling temperature, and strain hardening index $n$ and plastic strain ratio $r$ vs. coiling temperature are plotted according to the average values of mechanical properties (Table 2), as shown in Figs. 7 and 8, respectively. A similar 


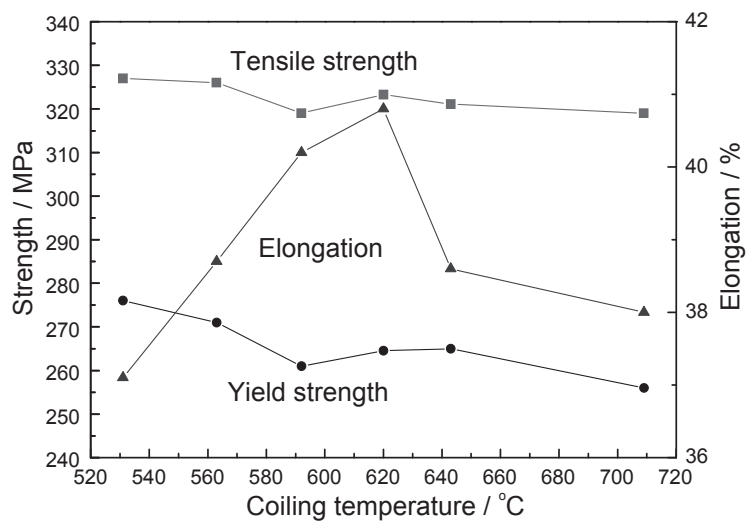

Fig. 7 Mechanical properties of the 08Al hot-rolled sheets subjected to cold rolling and annealing vs. the coiling temperature.

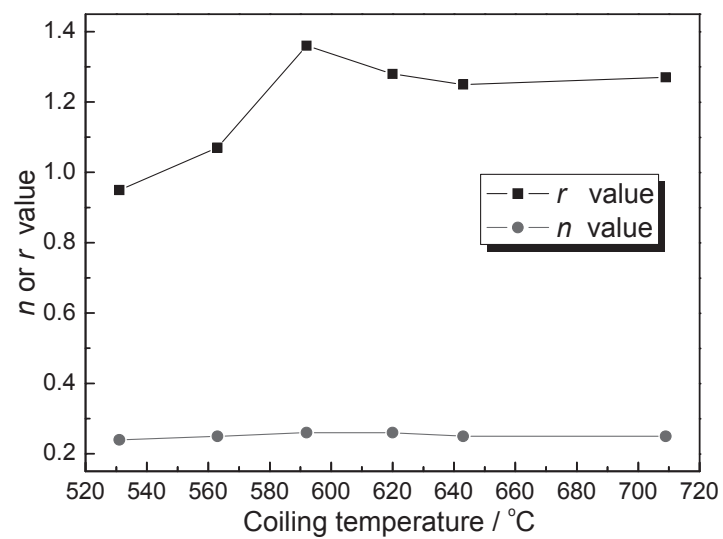

Fig. 8 Variations in $n$ and $r$ values of the 08Al hot-rolled sheets subjected to cold rolling and annealing with the coiling temperature.

variation tendency as the aforementioned case of hot rolled steel was found. The yield strength and tensile strength both firstly decrease and then increase with increasing coiling temperature, and almost reach a minimum at $592^{\circ} \mathrm{C}$ as well. The elongation firstly increases and then decreases with increasing coiling temperature, and achieves a maximum at $620^{\circ} \mathrm{C}$. From Fig. 8 , it can be seen that $n$ value nearly keeps stable with varying coiling temperature, while $r$ value firstly increases and then decreases, with a maximum occurring at $592^{\circ} \mathrm{C}$. Elongation is the highest $(40.8 \%)$ when coiled at $620^{\circ} \mathrm{C}$, which is somewhat different from that $(40.2 \%)$ at $592^{\circ} \mathrm{C}$. The $n$ and $r$ values are both the highest when coiled at $592^{\circ} \mathrm{C}$. The $r$ value is an important index indicating the deep drawing performance of steels. Therefore, on the basis of the mechanical properties of $08 \mathrm{Al}$ hot-rolled and coldrolled sheets, $592^{\circ} \mathrm{C}$ is thought to be the best coiling temperature for the studied steel within the scope of the present experiments.

The recrystallization after cold deformation is a nucleation and growth process in the metal. Normally orientations of the newly formed nucleus and grains are not randomly distributed. This process is determined by many factors, such as chemical properties of the matrix material, dislocation density and distribution, properties of impurities, deformation textures, recrystallization temperature and annealing time. ${ }^{15)}$ As mentioned above, $r$ value is closely related to the textures. ${ }^{14)}$ The best orientation that provides good deep drawing properties is $\{111\}\langle U V W\rangle$ and the worst orientation is $\{001\}\langle U V W\rangle$. The contrast between the above-mentioned texture components strongly influences the deep drawing performance index ( $r$ value). Thus, the larger the fraction of $\{111\}$ texture and smaller the fraction of $\{001\}$ texture, the better the deep drawing performance will be. The $r$ value increases as the ratio of $\{111\} /\{001\}$ increases. . $^{6-10)}$ Figure 9 shows the constant $\varphi_{2}$ orientation distribution function (ODF) sections obtained after cold-rolling and annealing of the hot-rolled sheets coiled at different temperatures. Figure 10(a) shows the variation in volume fraction of $\{111\}\langle U V W\rangle$ texture component with the coiling temperature. Apparently, the fraction of $\{111\}\langle U V W\rangle$ texture component first increases and then decreases with increasing coiling temperature, reaching a maximum at $592^{\circ} \mathrm{C}$. Figure 10(b) shows the variations in values of $\{111\}\langle U V W\rangle /$ $\{001\}\langle 110\rangle$ and $\{111\}\langle U V W\rangle /\{001\}\langle 100\rangle$ with the coiling temperature. It can be found that the both values decrease with increasing coiling temperature, and a maximum occurs at $592^{\circ} \mathrm{C}$. The $r$ value is the highest in the specimen coiled at $592^{\circ} \mathrm{C}$ (Fig. 8) and the result of texture analyses is completely consistent with that of the mechanical properties.

From Fig. 10(a), it can be seen that the volume fraction of advantageous $\{111\}$ texture component is low as the coiling temperature is too high or too low. As seen in Fig. 5(a) and (b), grains are thinner in the microstructures coiled at low temperatures $\left(531^{\circ} \mathrm{C}\right.$ and $\left.563^{\circ} \mathrm{C}\right)$. Hardening ability $(n)$ and drawing ability $(r)$ required by deep drawing are obtained through recrystallization annealing. According to the Morris equation: ${ }^{16)}$

$$
n=\frac{5}{10+d^{-1 / 2}}
$$

where $n$ is the strain hardening index ( $n$ value) and $d$ is the grain size. One can see that, as long as grain size is large enough, the $n$ value is high enough. Orange peel defect will generate when grains are too coarse, which is harmful to the stamping quality. Thus, the general requirements for the grain size of deep drawing steel is 6-8 grade. ${ }^{17)}$

As mentioned above, the strong $\{111\}\langle U V W\rangle$ texture is the most important for obtaining an excellent deep drawing property in the experimental steel. This kind of favorable texture is mainly controlled by the AIN precipitation, whereas AIN precipitation is dependent upon the coiling temperature during hot rolling. The main purpose of controlling coiling temperature is to prevent AIN precipitation during coiling but to make AlN precipitate during annealing. Fine AlN particles precipitated during annealing can hinder the recrystallization nucleation and inhibit grains owning a small driving force for nucleation when the experimental steel is annealed in the bell furnace. $\{111\}$ grains owning a large driving force are also hindered but dominant during the nucleation competition. AlN enhances the selectivity of nucleation, thus it contributes to the stronger $\{111\}$ texture.

AlN begins to precipitate at above $600^{\circ} \mathrm{C},{ }^{17)}$ therefore, the coiling temperature should be controlled below $600^{\circ} \mathrm{C}$. When the coiling temperature is higher than $600^{\circ} \mathrm{C}$ (e.g., $620^{\circ} \mathrm{C}-$ $709^{\circ} \mathrm{C}$ ), AlN precipitates during coiling, and AlN precipitates are thus rarely observed during the subsequent annealing, 

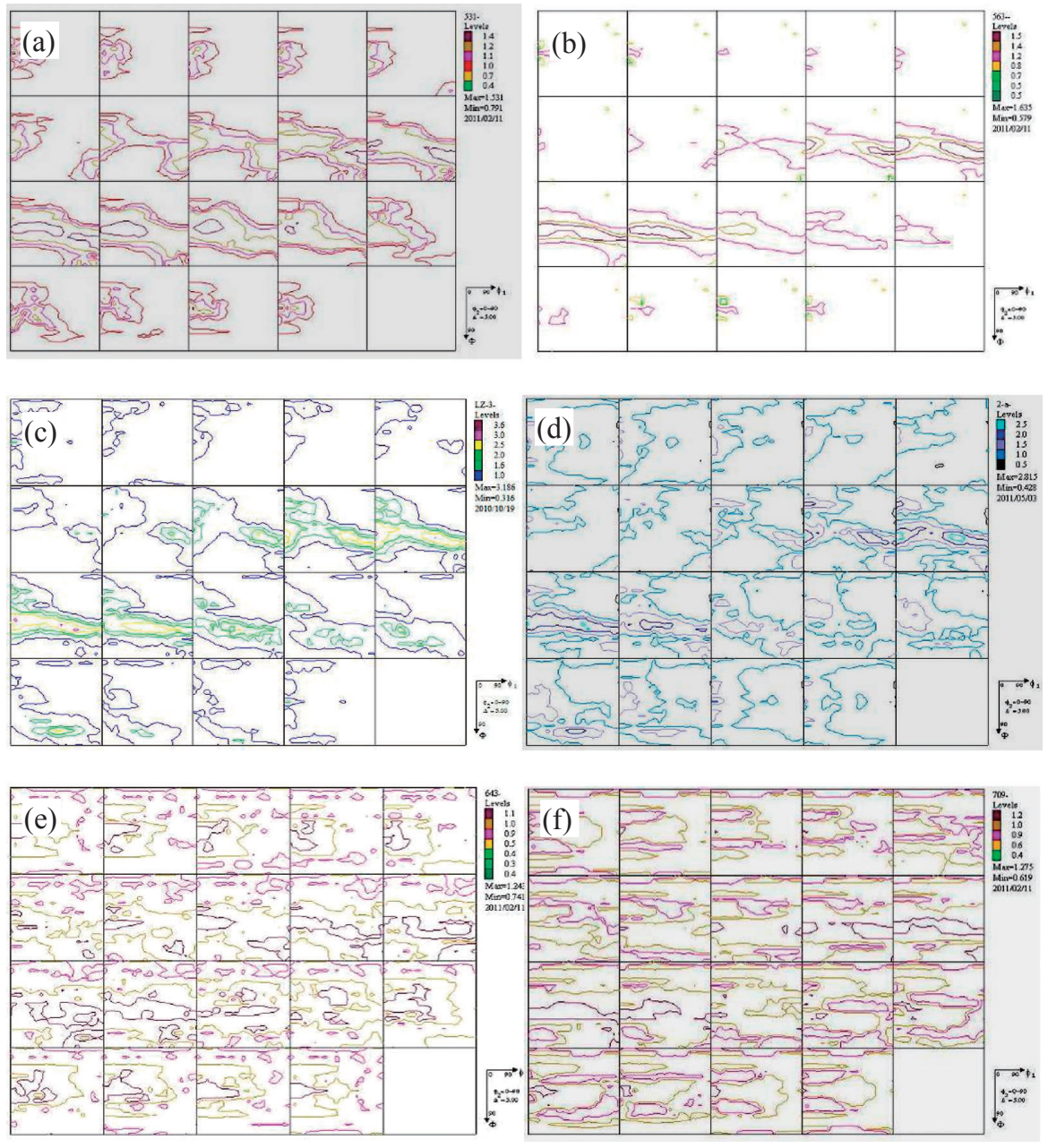

Fig. 9 Constant $\varphi_{2}$ ODF sections of the $08 \mathrm{Al}$ hot-rolled sheets coiled at different temperatures subjected to cold rolling and annealing. (a) $5311^{\circ} \mathrm{C}$; (b) $563^{\circ} \mathrm{C}$; (c) $592^{\circ} \mathrm{C}$; (d) $620^{\circ} \mathrm{C}$; (e) $643^{\circ} \mathrm{C}$; (f) $709^{\circ} \mathrm{C}$.
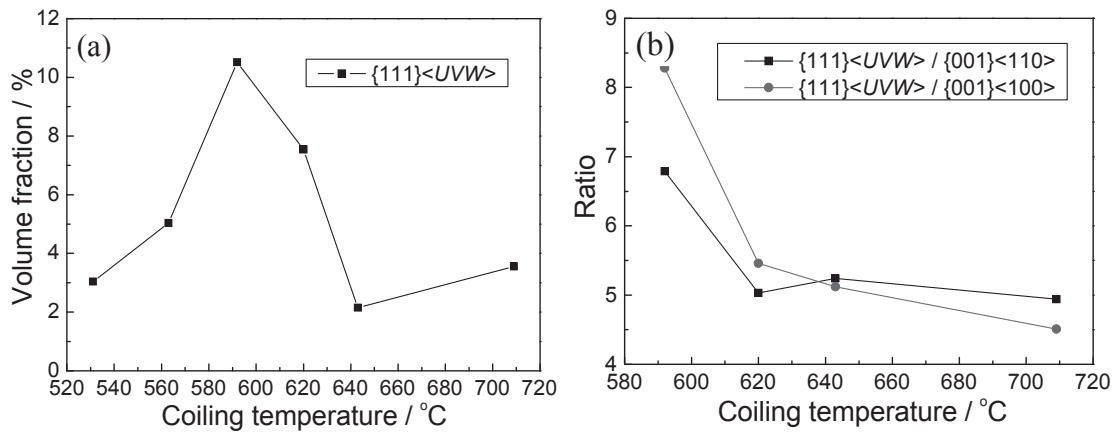

Fig. 10 (a) Variation in the volume fraction of $\{111\}\langle U V W\rangle$ texture component as a function of the coiling temperature. (b) Variation in the values of $\{111\}\langle U V W\rangle /\{001\}\langle 110\rangle$ and $\{111\}\langle U V W\rangle /\{001\}\langle 100\rangle$ as a function of the coiling temperature.

resulting in the weaker $\{111\}$ texture in the specimen of exorbitant coiling temperature. ${ }^{18,19)}$ Fine AIN particles preferentially precipitated during coiling hinder the growth of grains and will make the grains become equiaxed. ${ }^{17)}$ The shape of grains changes from pancake-like to equiaxed, and the proportion of equiaxed grains gradually increases in the annealed specimens with the coiling temperature ranging from $620^{\circ} \mathrm{C}$ to $709^{\circ} \mathrm{C}$ (Fig. 5(d)-(f)), which indicates that the amount of AlN precipitation becomes less during annealing but gradually increases during coiling with increasing coiling temperature in the experimental steel. In cold-rolled deep drawing steel, besides the effect of AlN precipitation, the grain size is the other influencing factor to the formation of favorable $\{111\}$ texture. When coiled at $531^{\circ} \mathrm{C}$ and $563^{\circ} \mathrm{C}$, microstructures after annealing are both inhomogeneous and fine in grain size (Fig. 5(a) and (b)). The $r$ value is proportional to the grain diameter. The larger $\{111\}$ grains absorb the smaller $\{100\}$ grains during grain growth and the large grains contribute to the strong textures. The favorable $\{111\}$ texture to the deep drawing property in the fine- 
grained microstructure is weaker than that in the coarsegrained microstructure. ${ }^{18,19)}$ Thus, the $r$ value is lower and the $\{111\}$ texture is weaker in the specimens coiled at $531^{\circ} \mathrm{C}$ and $563^{\circ} \mathrm{C}$ subjected to cold rolling and annealing (see Table 2 and Fig. 10(a)). When coiled at $592^{\circ} \mathrm{C}$, the grain size is moderate (Fig. 5(c)) and grains present the pancake-like shape (Fig. 6(c)), which is favorable to deep drawing property. This also proves that AlN precipitation occurs during annealing rather than during coiling under this coiling temperature.

Therefore, based on the results of microstructural observations, mechanical tests and texture analyses, it can be confirmed that drawing properties are the best in the experimental steel coiled at $592^{\circ} \mathrm{C}$ among the coiling temperatures selected in the present investigation.

\section{Conclusions}

(1) $08 \mathrm{Al}$ hot-rolled steel sheet, which is coiled at $592^{\circ} \mathrm{C}$, owns the good mechanical properties. After cold rolling and annealing, the experimental steel sheet can also obtain the optimal deep-drawability. The volume fraction of $\{111\}\langle U V W\rangle$ texture component is the highest and the values of $\{111\}\langle U V W\rangle /\{001\}\langle 110\rangle$ and $\{111\}\langle U V W\rangle /\{001\}\langle 100\rangle$ are the largest in the steel that undergoes cold rolling and annealing after the $592^{\circ} \mathrm{C}$ coiling.

(2) Both the strip-like and massive cementites appear in the cold-rolled and hot-rolled steel sheets when the coiling temperature is higher than $620^{\circ} \mathrm{C}$, which is harmful for the deep-drawability of the experimental steel. Therefore, the coiling temperature should be lower than $620^{\circ} \mathrm{C}$ in the $08 \mathrm{Al}$ cold-rolled deep drawing steel.

\section{Acknowledgments}

This work is supported by the National Natural Science Foundation of China (Nos. 51201027, 51271054 and 51231002).

\section{REFERENCES}

1) S. Mishra and C. Darmann: Int. Met. Rev. 27 (1982) 307-320.

2) B. H. Hahn and S. H. Kim: J. Korean Inst. Met. 24 (1986) 1323-1330.

3) B. C. Wu, F. Shi, X. Y. Cheng, R. M. Lin and C. M. Liu: Adv. Mater. Res. 194-196 (2011) 52-55.

4) S. K. Paul, U. Ahmed and G. M. Megahed: J. Mater. Eng. Perform. 20 (2011) 1163-1170

5) G. Xu, Y. Yang, X. Q. Zhang and H. Q. Zhang: ISIJ Int. 47 (2007) 1767-1771.

6) Q. Wang, P. P. Xia, L. X. He, X. G. Zeng and Y. L. Kang: Heat Treat. Met. 34 (2009) 45-48.

7) B. C. Wu, F. Shi, X. Y. Cheng, H. X. Zhang and C. M. Liu: Trans. Mater. Heat Treat. 32 (2011) 61-65.

8) X. Zhao, Z. C. Hu and L. Zuo: J. Mater. Sci. Technol. 22 (2006) 747750.

9) M. Jahazi and B. Egbali: J. Mater. Process. Technol. 103 (2000) 276279.

10) R. K. Ray, J. J. Jonas and R. E. Hook: Inter. Mater. Rev. 39 (1994) 129172.

11) A. I. Kestens Leo and R. Petrov: Ceram. Trans. 200 (2008) 207-216.

12) Z. C. Hu, C. S. He, X. Zhao and L. Zuo: J. Mater. Sci. 39 (2004) 42314234.

13) F. Terasaki and T. Kaneko: Sumitomo Met. 27 (1975) 1-9.

14) Y. L. Kang and X. J. Wang: 3th ICTP Conference Proceedings, Japan, (1990) p. 1251.

15) Y. Nagataki and Y. Hosoya: ISIJ Int. 36 (1996) 451-460.

16) B. W. Liang, X. D. Chen and Z. H. Wang: Formability of Sheet Metal, (China Machine Press, Beijing, 1999) p. 20.

17) D. X. Tian and P. H. Feng: Iron steel Res. 1 (1995) 54-58.

18) T. Urabe and J. J. Jonas: ISIJ Int. 34 (1994) 435-442.

19) W. B. Hutchinson: Acta Metall. 37 (1989) 1047-1056. 